\title{
Mid-infrared prediction of bovine milk fatty acids across multiple breeds, production systems, and countries
}

\author{
H. Soyeurt, ${ }^{*} \dagger^{1,2}$ F. Dehareng, $\ddagger^{1}$ N. Gengler, ${ }^{*} \dagger$ S. McParland,§ E. Wall, $\neq$ D. P. Berry,§ M. Coffey,\# \\ and P. Dardenne‡ \\ *Animal Science Unit, Gembloux Agro-Bio Tech, University of Liège, 5030 Gembloux, Belgium \\ †National Funds for Scientific Research, 1000 Brussels, Belgium \\ ‡Walloon Agricultural Research Centre, Valorisation of Agricultural Products, 5030 Gembloux, Belgium \\ $\S$ Teagasc Moorepark Dairy Production Research Centre, Fermoy, Co. Cork, Ireland \\ \#Sustainable Livestock Systems Group, Scottish Agricultural College, Bush Estate, Penicuik, Midlothian, EH26 OPH, United Kingdom
}

\begin{abstract}
Increasing consumer concern exists over the relationship between food composition and human health. Because of the known effects of fatty acids on human health, the development of a quick, inexpensive, and accurate method to directly quantify the fatty acid (FA) composition in milk would be valuable for milk processors to develop a payment system for milk pertinent to their customer requirements and for farmers to adapt their feeding systems and breeding strategies accordingly. The aim of this study was (1) to confirm the ability of mid-infrared spectrometry (MIR) to quantify individual FA content in milk by using an innovative procedure of sampling (i.e., samples were collected from cows belonging to different breeds, different countries, and in different production systems); (2) to compare 6 mathematical methods to develop robust calibration equations for predicting the contents of individual FA in milk; and (3) to test interest in using the FA equations developed in milk as basis to predict FA content in fat without corrections for the slope and the bias of the developed equations. In total, 517 samples selected based on their spectral variability in 3 countries (Belgium, Ireland, and United Kingdom) from various breeds, cows, and production systems were analyzed by gas chromatography (GC). The samples presenting the largest spectral variability were used to calibrate the prediction of FA by MIR. The remaining samples were used to externally validate the $28 \mathrm{FA}$ equations developed. The 6 methods were (1) partial least squares regression (PLS); (2) PLS + repeatability file (REP); (3) first derivative of spectral data + PLS; (4) first derivative + REP + PLS; (5) second derivative of spectral data + PLS; and (6) second derivative + REP +
\end{abstract}

\footnotetext{
Received May 6, 2010.

Accepted December 30, 2010.

${ }^{1}$ These authors contributed equally to the study.

${ }^{2}$ Corresponding author: hsoyeurt@ulg.ac.be
}

PLS. Methods were compared on the basis of the crossvalidation coefficient of determination $\left(\mathrm{R}^{2} \mathrm{cv}\right)$, the ratio of standard deviation of GC values to the standard error of cross-validation (RPD), and the validation coefficient of determination $\left(\mathrm{R}^{2} \mathrm{v}\right)$. The third and fourth methods had, on average, the highest $\mathrm{R}^{2} \mathrm{cv}, \mathrm{RPD}$, and $\mathrm{R}^{2} \mathrm{v}$. The final equations were built using all GC and the best accuracy was observed for the infrared predictions of C4:0, C6:0, C8:0, C10:0, C12:0, C14:0, C16:0, C18:0, C18:1 trans, C18:1 cis-9, C18:1 cis, and for some groups of FA studied in milk (saturated, monounsaturated, unsaturated, short-chain, medium-chain, and long-chain FA). These equations showed $\mathrm{R}^{2} \mathrm{cv}$ greater than 0.95 . With $\mathrm{R}^{2} \mathrm{cv}$ equal to 0.85 , the MIR prediction of polyunsaturated FA could be used to screen the cow population. As previously published, infrared predictions of FA in fat are less accurate than those developed from FA content in milk (g/dL of milk) and no better results were obtained by using milk FA predictions if no corrections for bias and slope based on reference milk samples with known contents of FA were used. These results indicate the usefulness of equations with $\mathrm{R}^{2} \mathrm{cv}$ greater than $95 \%$ in milk payment systems and the usefulness of equations with $\mathrm{R}^{2} \mathrm{cv}$ greater than $75 \%$ for animal breeding purposes.

Key words: mid-infrared, milk, fatty acid

\section{INTRODUCTION}

Traditionally, milk quality from dairy cattle refers to fat and protein content or the number of somatic cells or total bacteria in the milk. However, increasing consumer concern exists over the relationship between food composition and human diseases such as cardiovascular disease and cancer. Therefore, the subject of milk quality should be expanded to include characteristics with proven associations with human health. The nutritional quality of bovine milk is largely related to the milk fat content and composition. Bovine milk fat is composed of, on average, $96 \%$ triacylglycerols made 
up of a molecule of glycerol and 3 esterified fatty acids (FA; Jensen, 1995). Three classes of FA exist, based on the number of double bonds present in their chemical structure: saturated fatty acids (SFA, no double bond), monounsaturated fatty acids (MUFA, one double bond), and polyunsaturated fatty acids (PUFA, more than one double bond). The latter 2 classes (MUFA and PUFA) make up the unsaturated group of FA (UFA). Many studies have documented the potential effects of dietary FA on human health (e.g., Williams, 2000). Therefore, quick, inexpensive, and accurate methods to quantify the FA composition of milk would be valuable for milk processors to develop a payment system for milk pertinent to their customer requirements and for farmers to adapt their feeding systems accordingly. Such tools would also be useful to animal breeders in a long-term strategy of breeding for milk with a FA composition sought by consumers.

Until recently, the only method used to quantify FA content in milk was a method based on GC after a step of extraction, followed by saponification and transmethylation. Although this method is accurate and yields detailed information about the FA of milk samples (Collomb and Bühler, 2000), it is expensive and time consuming and therefore not feasible for routine analysis of the large number of samples necessary for management or breeding purposes. Several studies (Soyeurt et al., 2008a,b; Rutten et al., 2009) have documented the potential of using mid-infrared (MIR) spectrometry to quantify the major FA in cow milk. The MIR spectrum represents the absorptions of infrared rays at frequencies correlated to the vibration of specific chemical bonds within a molecule. Therefore, the MIR milk spectrum represents the chemical composition of milk. The approach proposed by Soyeurt et al. (2008a,b) to quantify the milk FA contents used milk samples from multiple breeds based on the assumption that changes in the milk MIR regions related to FA were proportional to the contents of FA in milk and that these relationships were similar across breeds. Rutten et al. (2009) hypothesized that the changes in the spectral data related to the FA profile (i.e., the relationship among FA) could be different during winter and summer, and they developed calibration equations within season to improve the accuracy of prediction. However, they concluded that these equations did not improve the predictive ability of milk FA from MIR spectrometry.

The method of choice currently used for relating MIR spectra to milk fatty acid is partial least squares (PLS) without any pretreatment of the spectral data (Soyeurt et al., 2006, 2008a,b; Rutten et al. 2009). Equations with improved predictive ability for milk FA compo- sition developed using different statistical approaches such as pretreatment of spectral data are lacking.

The objectives of this study were (1) to confirm the ability of MIR to quantify individual FA content in milk by using an innovative procedure of sampling across multiple breeds, multiple countries, and multiple production systems; (2) to compare 6 mathematical methods to improve the robustness of calibration equations for predicting the contents of individual FA in milk; and (3) to show interest in using the FA equations developed in milk basis to predict FA content in fat without corrections of slope and bias based on reference milk samples with known contents of FA.

\section{MATERIALS AND METHODS}

\section{Collected Samples}

Samples of milk (40 mL) available for this study contained bronopol preservative $(0.5 \mathrm{~mL})$ and were collected between March 2005 and December 2009 in Belgium, between April 2009 and August 2009 in Ireland, and in August 2009 in the UK. All milk samples were analyzed using MilkoScan FT6000 spectrometers (Foss, Hillerød, Denmark), which output 1 spectrum for each milk sample analyzed, containing 1,060 data points in the infrared range from 900 to $5,000 \mathrm{~cm}^{-1}$. Belgian milk samples were analyzed in the milk laboratory "Comité du lait" (Battice, Belgium) and the other samples were analyzed at Moorepark (Fermoy, Cork, Ireland). All spectra were generated directly without using the calibration mode of the spectrometer because direct access to the spectral data was available in the 2 milk laboratories.

A total of 1,609 milk samples were collected from 8 herds in the Walloon Region of Belgium between March 2005 and May 2006 during routine milk recording and frozen at $-26^{\circ} \mathrm{C}$. These milk samples, containing $50 \%$ morning milk and $50 \%$ evening milk, were from 475 cows representing 6 dairy breeds (dual-purpose Belgian Blue, Holstein, Jersey, Normande, Montbeliarde, and Red and White). Herds were chosen based on their variability in milk fat content, their geographical location, and the number of breeds in each herd. Because it was not feasible to undertake GC on all samples, a selection of 78 samples were chosen based on maximizing the spectral variability of the samples, determined using a principal component analysis (PCA) approach. This approach identifies the spectra that are most useful in development of prediction equations.

To further increase the variability of milk samples with different MIR spectra, additional samples were collected from the Walloon Region of Belgium be- 
tween June 2006 and December 2009. Using PCA, the MIR spectra of bulk milk samples and individual cow samples (a mix of 50\% morning milk and 50\% evening milk), routinely collected and analyzed in the Belgian milk laboratory (Comité du Lait), were compared with the spectra of the 78 initially selected samples. Milk samples whose MIR spectra differed, based on the PCA, from the previously collected samples were retained. In total, an additional 210 samples were selected using this method and frozen pending GC analysis.

The MIR spectra of weekly milk samples from Teagasc research herds in Ireland and monthly milk samples from the Langhill lines of dairy cattle kept in the Crichton research herd (Scotland) were also compared, using PCA, with the samples previously stored in Belgium. The number of milk samples chosen to further increase the variability within the data set of MIR spectra was 144 in Ireland and 106 in Scotland. All of these samples (morning or evening milks) were frozen at $-20^{\circ} \mathrm{C}$ pending the GC analysis. The cows sampled in the Irish research herds were fed predominantly grazed grass and consisted of animals of different breeds (Prendiville et al., 2010) and different strains of Holstein-Friesian (Coleman et al., 2009). Cows from Scotland were from 2 genetically divergent lines (divergent for milk solids) and were fed 2 different diets (Coffey et al., 2004). Approximately half were fed a predominantly forage only diet and the other half a diet consisting of approximately $60 \%$ silage and $40 \%$ concentrates.

The multiple breed, multiple countries, and multiple production approach proposed in this study to collect the samples used to develop the calibration equations allowed us to cover the natural variability of fatty acids in bovine milk.

\section{Measurement of FA}

In total, 538 frozen milk samples from Belgium, Ireland, and Scotland with MIR spectral data were analyzed by GC. The contents of FA in each milk sample were quantified by GC with a methodology similar to that described by Soyeurt et al. (2008a); analyses of all 538 samples were undertaken by the Agricultural Walloon Research Centre (Gembloux, Belgium). The milk fat was extracted according to ISO standard 14156:2001 (ISO, 2001). Preparation of FA methyl esters was made following ISO standard 15884:2002 (ISO, 2002). These milk fat samples were analyzed using GC from the method developed by Collomb and Bühler (2000). The gas chromatograph (model 6890N, Agilent Technologies Inc., Palo Alto, CA) was equipped with a CPSil-88 capillary column (Varian Inc., Palo Alto, CA) with a length of $100 \mathrm{~m}$, an internal diameter of $0.25 \mathrm{~mm}$, and a film thickness of $0.20 \mu \mathrm{m}$. The condi- tions for the chromatographic analyses were as follows: carrier gas, helium; average velocity, $19 \mathrm{~cm} / \mathrm{s}$; cold on-column injector; flame-ionization detector at $255^{\circ} \mathrm{C}$; and a temperature program from $60^{\circ} \mathrm{C}(5 \mathrm{~min})$ to $165^{\circ} \mathrm{C}$ (at $14^{\circ} \mathrm{C} / \mathrm{min}$ ) for $1 \mathrm{~min}$, and then $165^{\circ} \mathrm{C}$ to $225^{\circ} \mathrm{C}$ (at $2^{\circ} \mathrm{C} / \mathrm{min}$ ) for $17 \mathrm{~min}$. The volume injected was $0.5 \mu \mathrm{L}$. An anhydrous milk fat with a certified FA composition (reference material BCR-164, obtained from the Commission of the European Communities, Brussels, Belgium) was used to determine the FA methyl ester response factors, the repeatability, and the accuracy of this method. For all studied FA, the coefficient of variation $[(\mathrm{SD} /$ mean $) \times 100]$ was $<3.5 \%$, suggesting good repeatability of GC data.

The FA contents were expressed in grams per deciliter of milk using the content of fat predicted by the MilkoScan FT6000 (Foss). This prediction was considered in this publication as the reference fat content for 2 reasons. The ability of MIR to quantify the content of fat is high and the accuracy of the fat prediction is regularly checked by the milk laboratory using reference samples with known fat content. The error of prediction of fat content on the Belgian MilkoScan FT6000 spectrometers used from the data collected in 2009 from 179 spectra was equal to $0.2 \mathrm{~g} / \mathrm{dL}$ of milk. The group of short-chain FA (SCFA) included FA with between 4 and 10 carbons (C) in their structure. Medium-chain FA (MCFA) included FA whose structures contained between 12 and $16 \mathrm{C}$, whereas long-chain FA (LCFA) included FA with structures containing between 17 and $22 \mathrm{C}$.

A PCA was undertaken across all FA, and the Mahalanobis distance was calculated. As described by Williams (2007), an outlier sample or spectrum is a sample or spectrum that differs from the mean of the population by 3 or more times the Mahalanobis distance. Using this threshold, 21 samples were deemed outliers and discarded. The final data set contained 517 samples.

\section{Calibration and Validation Set}

An initial calibration data set of 220 samples was generated using only the samples from the Walloon region of Belgium. To augment the variability of the MIR spectra in this data set, 47 samples from Belgium ( $\mathrm{n}=$ $31)$, Ireland $(\mathrm{n}=12)$, and Scotland $(\mathrm{n}=4)$ were identified using PCA and added to the calibration data set. The samples from each country were not balanced in the calibration set because the majority of milk samples collected in Ireland and Scotland showed a spectral variability already existing in the Walloon data set. Only informative samples were added. Therefore, the calibration data set used in this study contained 267 samples 
and the remaining 250 samples were included in the external validation data set (16 samples from Belgium, 132 from Ireland, and 102 samples from Scotland).

\section{Development of Prediction Equations}

In this study, 6 approaches were used to develop the most accurate prediction equations:

- Method 1: PLS and no pretreatment on the spectral data;

- Method 2: PLS + the use of a repeatability file;

- Method 3: PLS + the use of a first-derivative pretreatment on the spectral data;

- Method 4: PLS + the use of a first-derivative pretreatment + repeatability file;

- Method 5: PLS + the use of a second-derivative pretreatment;

- Method 6: PLS + the use of a second-derivative pretreatment + repeatability file.

To make the spectral data linear, the initial spectral data expressed in transmittance were converted in absorbance by taking the $\log _{10}$ of the reciprocal of transmittance.

An equation developed for one spectrometer could provide results slightly biased on another instrument. To improve the repeatability across instruments, a file referred to throughout this paper as the "repeatability file" was generated by recording the MIR spectrum of several milk samples provided by different spectrometers. In the present study, the MIR spectra of 108 samples were determined on at least 2 different spectrometers. A total of 5 different MilkoScan FT6000 (Foss) were used: 3 located in a Belgian milk laboratory (Comité du Lait), 1 located in Luxembourg (Convis Herdbuch, Ettelbruck, Luxembourg) and 1 located in Ireland (Teagasc Moorepark, Co. Cork, Ireland). The approach taken to use the repeatability file in the development of equations was similar to that described by Westerhaus (1990). As explained by Westerhaus (1990), each spectrum was centered by subtracting the average of all spectra for the samples included in the repeatability file (i.e., 108 selected samples). The reference $\mathrm{GC}$ values for these centered samples (i.e., composition of FA) were equal to zero. The samples in the repeatability file were then used to extend the initial calibration set. This method creates a decrease in the repeatability error. The repeatability of spectral data for the infrared regions considered was on average lower than $2 \%$.

The derivative of the spectral data was obtained to "sharpen" the absorption bands. First and second derivatives were obtained using the following formula:

$$
d x_{k}=x_{k-\frac{g-1}{2}}-x_{k+\frac{g-1}{2}},
$$

where $d x_{k}$ is the value of the derivative for the spectral data point $k$, and $g$ is an odd integer strictly positive titled "gap" (i.e., 5 consecutive spectral data points in this study; Hruschka, 1987). The second derivative used the absorbance obtained for the first derivative instead of the absorbance of spectra.

A cross-validation approach using 20 groups of samples from the calibration set was used to determine the most appropriate number of factors for the prediction equation of each FA and to assess the robustness of calibration. Cross-validation leaves out one group at a time and performs a calibration with the remaining 19 groups. Then, the calibration was applied to the one group left out and then repeated 20 times with a different group left out each time. Therefore, crossvalidation is an internal validation because it uses the same samples for validation and calibration. The maximal number of factors per equation was 16 .

The calibration coefficient of determination $\left(\mathbf{R}^{2} \mathbf{c}\right)$ was calculated as the square of the correlation coefficient between the reference GC data and their corresponding predicted values calculated from the final model based on all samples included in the calibration set. The standard error of calibration (SEC) was calculated as

$$
S E C=\sqrt{\frac{\sum_{i=1}^{N}\left(\hat{y}_{i}-y_{i}\right)^{2}}{N-p-1}},
$$

where $\hat{y}_{i}$ was the predicted values obtained for the sample $i$ included in the calibration set; $y_{i}$ was the reference GC value of the sample $i$; $N$ was the number of samples in the calibration set; and $p$ was the number of factors used to build each calibration equation. The standard error of cross-validation (SECV) was calculated as

$$
S E C V=\sqrt{\frac{\sum_{j=1}^{Z} \sum_{i=1}^{N}\left(\hat{y}_{i, j}-y_{i, j}\right)^{2}}{N}},
$$

where $\hat{y}_{i, j}$ was the predicted values obtained for the sample $i$ in the group of cross-validation $j ; y_{i, j}$ was the reference $\mathrm{GC}$ value the for the sample $i$ in the group of cross-validation $j ; N$ was the number of samples in each group of cross-validation; and $Z$ was the number of cross-validation groups. 
The cross-validation coefficient of determination $\left(\mathbf{R}^{2} \mathbf{c v}\right)$ was calculated as the square of the correlation coefficient between the reference GC data and their corresponding predicted values calculated from the results obtained by the 20 models developed during the cross-validation.

The mean and SD for each FA measured using GC were calculated for the validation and calibration sets. The best calibration equation should have the larger $\mathrm{SD}$ for GC data (to cover the natural range of FA variability) and the smallest SECV. Therefore, the ratio of SD from GC data to SECV was calculated (RPD; Williams and Sobering, 1993). If this ratio is greater than 3 , the prediction given by the developed calibration equation can be considered good.

By observing the spectral variation (Soyeurt et al., 2010 ), we decided to develop the calibration from 3 specific regions located between 926 and 1,600 $\mathrm{cm}^{-1}$, 1,712 and $1,809 \mathrm{~cm}^{-1}$, and 2,561 and $2,989 \mathrm{~cm}^{-1}$. The selection of MIR regions for calibration is less important with the use of a repeatability file because the use of this file will permit a decrease in the PLS coefficient for wavelength with poor repeatability (Hruschka, 1987).

\section{External Validation}

The equations developed by the 6 proposed methods were also externally validated using the 250 independent samples. The validation coefficient of determination $\left(\mathbf{R}^{2} \mathbf{v}\right)$ was calculated using the same formula shown to calculate $R^{2}$ c except that the values were calculated from the validation set. The 6 studied methods were compared based on $\mathrm{R}^{2} \mathrm{cv}, \mathrm{RPD}$, and $\mathrm{R}^{2} \mathrm{v}$.

\section{Accuracy of Calibration}

To assess the accuracy of mid-infrared prediction of FA, all samples with FA content data available were combined in a final data set $(\mathrm{n}=517$ samples $)$ and the equations were rebuilt using the best method derived from the results obtained with the calibration and validation data. To improve the robustness of equations, the critical $\mathrm{T}$ outlier value (Winisi software, Foss) was set to 2.5 (i.e., recommended default value). If the difference between the predicted and reference FA values was greater than 2.5 times the SEC, the sample was considered to be an outlier and deleted. This methodology was iterated twice. To ensure a good comparison of methods, this methodology of outlier detection was not used in the first part of this study because the samples considered as outliers were not the same for the 6 studied methods. It is logical, because this method is based on differences between predicted and reference values. So, this method is influenced by the accuracy of developed equations. As shown later, the 6 methods gave different error values.

\section{RESULTS AND DISCUSSION}

\section{Descriptive Statistics}

Forty-seven samples were selected based on their spectral variability from the Irish and Scottish samples and the 49 remaining Belgian samples. This low number of additional selected samples (i.e., 47) demonstrated the high natural spectral variability already covered by the initial Belgian calibration set, which comprised 221 milk samples. This was expected, because the initial data set included milk samples representative of varying seasons, years, and geographical location from cows of different parity, stage of lactation, and breed.

Mean, SD, minimal and maximal values, and the coefficient of variation $(\mathrm{CV})$ of the GC data used in the calibration and validation sample sets are presented in Table 1 . The variability of FA profile in the calibration set used in this study can be considered as high based on the values of $\mathrm{CV}$ calculated for each studied FA. $\mathrm{CV}$ ranged from 8.97 to $60.05 \%$. The CV, minimal, and maximal values shown in Table 1 for the external validation set demonstrate that the variability of GC data in this set was lower than that shown in the calibration set except for the group of C18:2, and branched FA, C18:2 cis-9,cis-12, and C18:2 cis-9,trans-11. These figures confirm the high range of natural variability of FA present in the sample set used to build the calibration equations. This variation, which is larger than previously published estimates (Rutten et al., 2009), resulted from the careful selection of samples for entry to the calibration data set based on spectral variability.

\section{Comparison of Methods to Develop Calibration Equations for FA in Milk}

Table 2 summarizes the $\mathrm{R}^{2} \mathrm{cv}, \mathrm{RPD}$, and $\mathrm{R}^{2} \mathrm{v}$ calculated for each calibration equation built from all studied methods and FA contents in milk (g/dL of milk). The RPD ratio is useful to compare the methods studied because, by definition, RPD considers SECV and the variability of the calibration set simultaneously. Therefore, RPD is more sensitive than $\mathrm{R}^{2} \mathrm{cv}$. For instance, the $\mathrm{R}^{2} \mathrm{cv}$ for fat and SFA calibration equations were equal but RPD were different.

The best calibration equation has to have the highest $\mathrm{R}^{2} \mathrm{cv}$, RPD, and $\mathrm{R}^{2} \mathrm{v}$. Method 4 (PLS + first derivative + repeatability file) gave the best prediction results for the majority of studied FA (see results in bold face in Table 2) because this method has simultaneously more often the highest values for $\mathrm{R}^{2} \mathrm{cv}, \mathrm{RPD}$, 
Table 1. Descriptive statistics of gas chromatographic data for the calibration and validation sample sets

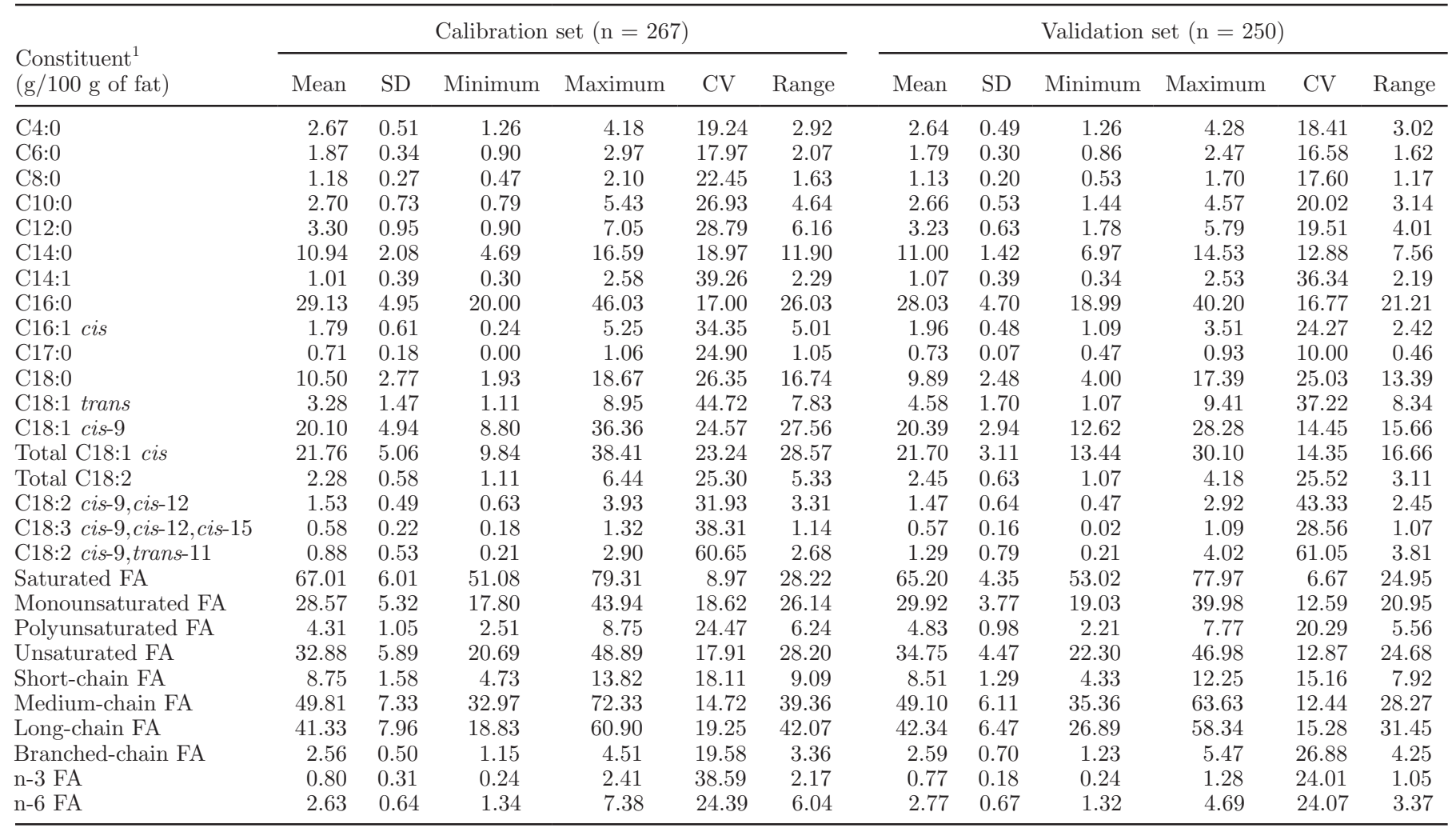

${ }^{1}$ Short-chain fatty acids $(\mathrm{FA})=\mathrm{C} 4$ to $\mathrm{C} 10$; medium-chain $\mathrm{FA}=\mathrm{C} 12$ to $\mathrm{C} 16$; long-chain $\mathrm{FA}=\mathrm{C} 17$ to $\mathrm{C} 22$.

and $\mathrm{R}^{2} \mathrm{v}$. This conclusion was expected. Inclusion of spectra provided by separate spectrometers from milk samples of individual cows of different breeds and countries on varying feeding systems resulted in increased noise (e.g., baseline drift) and explains the need for pretreatment of the data before the development of the calibration equations. As explained previously, the repeatability file used in method 4 allows us to account for the repeatability of each spectral data point. Even if differences between the use of a repeatability file and no repeatability file (methods 3 and 4, Table 2) were not very large (the $P$-values between methods using a repeatability file and the others were $<5 \%$ ), the use of the first derivatives improved the accuracy of MIR prediction for FA (comparison between methods 2 and 4, Table 2). The first derivatives corrected for the baseline drift evident in the spectra file (Figure 1). The use of the first derivative was also suggested by Dal Zotto et al. (2008). These authors noted that the use of the first derivative on spectral data improved the accuracy of the equations predicting milk rennet coagulation time and curd firmness. The second derivative, which removes the linear trend from the spectral data, did not have a statistically significant effect in this study.

The PLS method without pretreatment (method 1) did not give the best predictions except for predictions of C17:0 and n-3 FA (Table 2). However, these equations had $R^{2} c v$ and RPD values that were too low to be considered useful. In fact, for potential qualitative and quantitative applications, a calibration equation should have $\mathrm{R}^{2} \mathrm{cv}$ and $\mathrm{RPD}>0.80$ and $>3$, respectively (Williams, 2007). This was the case for the most individual FA and groups of FA: C6:0, C8:0, C10:0, C12:0, C14:0, C16:0, C18:1 cis-9, C18:1 cis, SFA, MUFA, UFA, SCFA, MCFA, and LCFA. However, in previous studies (Soyeurt et al., 2006, 2008a,b; Rutten et al., 2009), calibration equations were developed using just a PLS approach without pretreatment of spectral data. Even if the conclusion about the efficiency of calibration equations to predict the contents of FA shown by Rutten et al. (2009) was similar, this study showed the better fitting given by the PLS method including derivative pretreatment on spectral data compared with the PLS method used alone.

Generally, the highest $\mathrm{R}^{2} \mathrm{cv}$ and RPD were observed for the studied groups of FA (Table 2). Therefore, as shown by Soyeurt et al. (2006) and Rutten et al. (2009), the efficiency of MIR prediction of FA depends on the concentrations of FA in milk. The correlation between the average concentration of FA in the calibration set and the corresponding $\mathrm{R}^{2} \mathrm{cv}$ was positive and equal to 0.59 . Moreover, the calibration set for each studied trait should also 


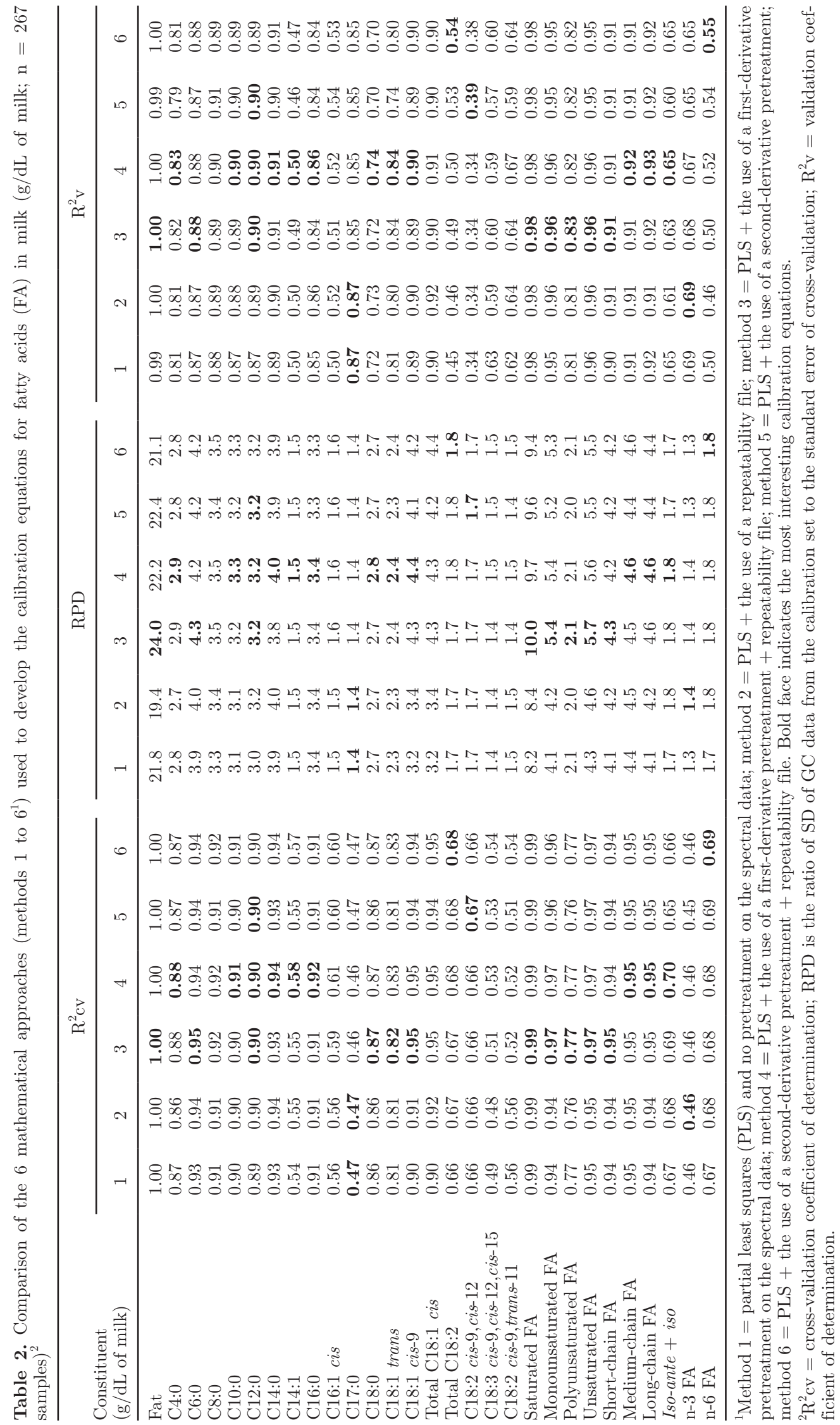




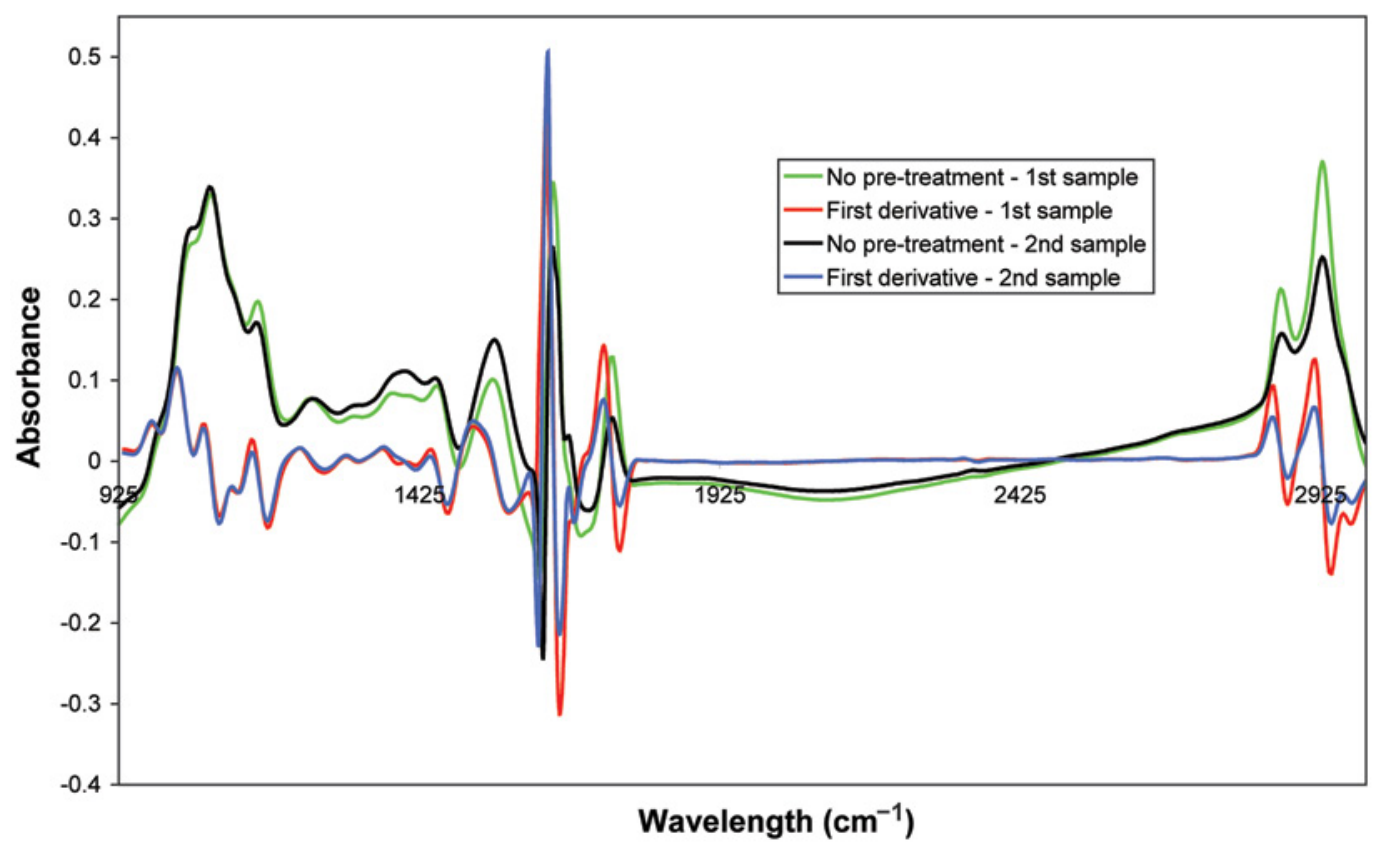

Figure 1. Effect of first derivative on 2 mid-infrared milk spectra.

be variable. In a regression including the mean and SD of GC data expressed in milk, SD explained more than $36 \%$ of the variability of $\mathrm{R}^{2} \mathrm{cv}$ obtained. Consequently, the infrared prediction should be improved if the FA yield in milk is high and the content of the considered FA is variable within the calibration set. A similar correlation of 0.55 was obtained using the validation set.

The best method differed depending on the studied FA traits even if the use of the first derivative seemed to be the best approach with or without the repeatability file (see results in bold face in Table 2). Fat content, C6:0, C18:0, C18:1 trans, C18:1 cis-9, SFA, MUFA, PUFA, UFA, and SCFA seemed to be slightly better predicted by method 3. In contrast, C17:0 and the group of n-3 FA were better predicted using method 2. Moreover, the predictions obtained for the total content of C18:2 and $\mathrm{C} 18: 2$ cis-9, cis-12 seemed to be more accurate from methods 5 and 6 , respectively (i.e., greater $\mathrm{R}^{2} \mathrm{v}, \mathrm{RPD}$, and $\mathrm{R}^{2} \mathrm{cv}$ ). However, these differences were slight and thus suggested that the use of method 4 could be the best for all studied FA traits.

\section{Prediction of FA in Fat Based on FA Predictions in Milk}

As shown in earlier studies (Soyeurt et al., 2006; Rutten et al., 2009), the prediction of FA in fat by MIR spectrometry is not sufficiently accurate. However, some equations with relatively high accuracy were developed to quantify some FA contents in milk (Table 2). Table 3 summarizes the accuracy of predicting FA content in fat from using equations developed to predict milk FA content in the milk and the total fat content. Three different measures of total fat content were considered: reference fat content obtained by the MIR spectrometer and corrected if needed by the bias and the slope, fat content predicted by method 4 (globally the best for all FA, Table 2), and method 3 (the best method to predict fat, Table 2). For each FA trait, 2 predictions were used: those given by method 4 and those given by the best method found based on the results presented in Table 2. Based on the results of the calibration set, it appears that this FA prediction in fat using FA predicted in milk gave better results than the one observed by the direct prediction in fat for C6:0, C12:0, C18:2 cis-9,cis-12, SFA, and SCFA. It was neutral for C8:0, C10:0, C14:0, C18:2 cis-9,trans-11, MUFA, UFA, and branched FA.

For some groups of FA, it is possible to extend this approach. For instance, it is possible to estimate the content of UFA in fat using the content of SFA in fat or in milk and divided by the fat content. In the same way, PUFA can be predicted using MUFA and UFA or fat content, SFA, and MUFA. All of these possibilities were tested but the best results (i.e., highest $\mathrm{R}^{2} \mathrm{cv}$ ) were those present in Table 4 . The accumulation of errors could explain this observation.

\section{Accuracy of Calibration}

To give an idea of the accuracy of each infrared prediction, Table 4 presents the best approach for each 
Table 3. Coefficient of determination between the reference GC data and the prediction (Pred.) of fatty acid (FA) contents in fat (g/100 g of fat) obtained from the predictions of fatty acid in milk ( $\mathrm{g} / \mathrm{dL}$ of milk)

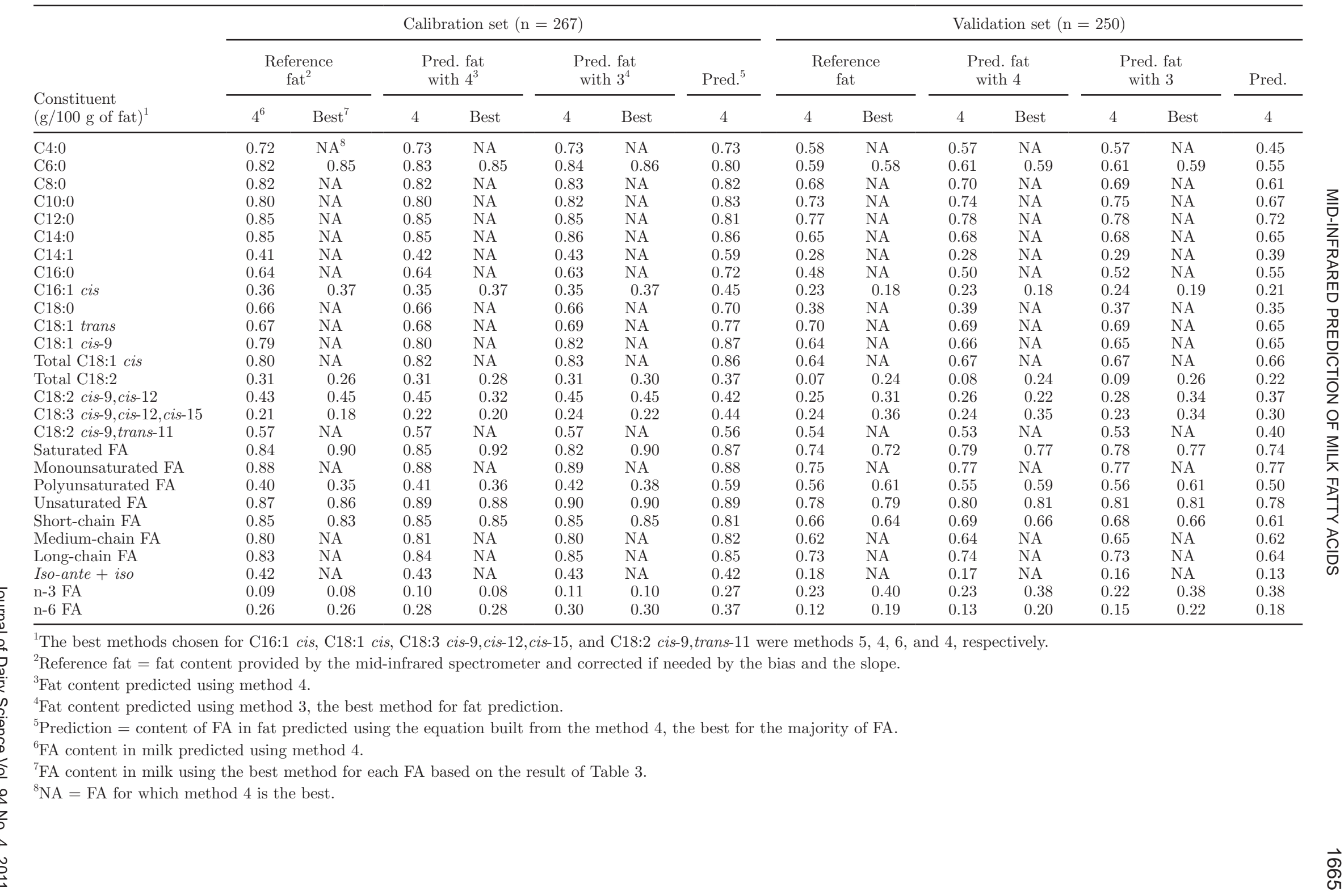


Table 4. Accuracy of mid-infrared predictions for fatty acid (FA) in milk (g/dL of milk) using the entire data set ${ }^{1}$

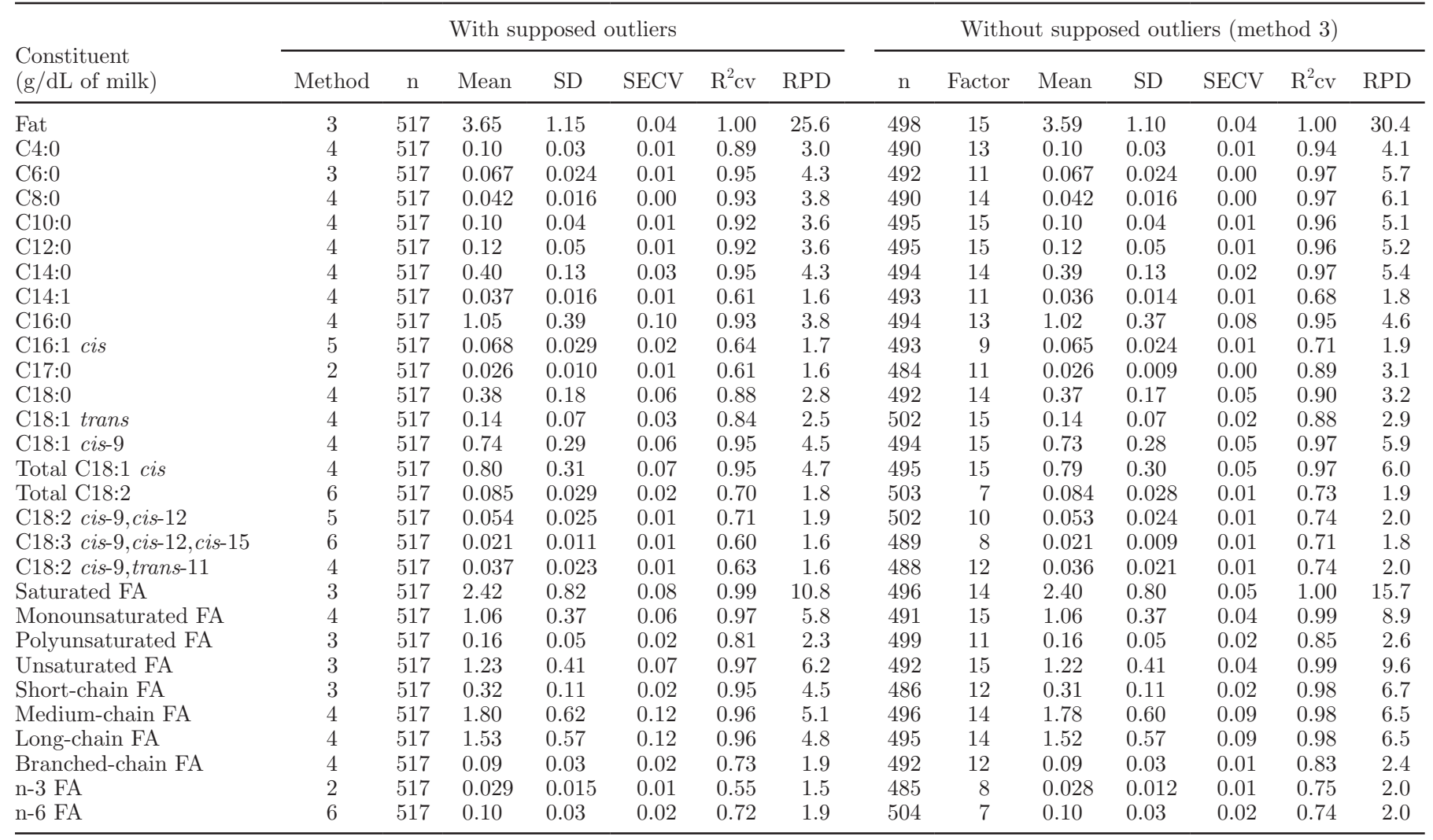

${ }^{1} \mathrm{SECV}=$ standard error of cross-validation; $\mathrm{R}^{2} \mathrm{cv}=$ cross-validation coefficient of determination; $\mathrm{RPD}=\mathrm{ratio}$ of $\mathrm{SD}$ of $\mathrm{GC}$ data from the calibration set to the SECV.

studied FA using the entire data set $(\mathrm{n}=517)$ together with the corresponding descriptive statistics, SECV, $\mathrm{R}^{2} \mathrm{cv}$, and RPD. The RPD calculated using the entire data set was generally greater than the RPD shown in Table 2 (calculated using only the samples in the calibration data set). In contrast to Table 3, no difference was observed between methods 3 and 4 . Method 3 was the best predictor for the majority of FA (data not shown). The similarity of results obtained using method 3 and method 4 can be easily explained by the introduction of new samples in the calibration set. As explained previously, the samples included in the validation (and thus used in the calibration set) came mainly from Ireland and Scotland. The introduction of more spectra coming from other regions in the calibration set decreased the relevance of using the repeatability file in the development of calibration equations. The larger data set resulted in an improved ability of MIR spectrometry to quantify the studied PUFA.

The second part of Table 4 shows the results for the new FA calibration equations built using outlier detection and method 3. The number of factors per equation ranged from 7 to 15 . Following the removal of outliers, the RPD calculated for all or most FA was higher, indicating that the removal of outliers improves the accuracy. The same equation as the one isolated previously from Table 2 for potential quantitative and qualitative applications can be considered from Table 4 and showed a greater RPD threshold (4 instead of 3 ). Based on a RPD threshold equal to 3, 3 additional equations can be used: C4:0, C18:0, and C18:1 equations. With $\mathrm{R}^{2} \mathrm{cv}>0.75$, the MIR predictions of PUFA, n-3 FA, and the group of branched FA could be used to screen the cow population. So for all of these equations, the $95 \%$ confidence interval of the population will be 1.96 times SECV.

\section{CONCLUSIONS}

This study compared 6 methods used to develop calibration equations for predicting the contents of FA in milk by using an innovative approach to collect milk samples combining multiple breeds, countries, and production systems. Globally, the methods using a firstderivative pretreatment of the spectral data gave the best predictions. The best accuracy was observed for infrared predictions of C4:0, C6:0, C8:0, C10:0, C12:0, C14:0, C16:0, C18:0, C18:1 trans, C18:1 cis-9, C18:1 cis, 
and for the majority of studied groups of FA studied in milk. With $\mathrm{R}^{2} \mathrm{cv}>0.75$, the MIR predictions of PUFA, n-3 FA, and the group of branched FA could be used to screen the cow population. As already published, the infrared predictions of FA in fat are less accurate and no improvement was obtained by using the developed equations for fat and for FA in milk without corrections of slope and bias based on milk samples with known contents of FA. The large number of samples, specifically chosen to cover the natural variation in milk FA present, coupled with the high accuracy of selection for some FA, indicates the usefulness of these equations in milk payment systems (if $\mathrm{R}^{2} \mathrm{v}$ is $>95 \%$ ) and animal breeding (if $\mathrm{R}^{2} \mathrm{cv}$ is $>75 \%$ ).

\section{ACKNOWLEDGMENTS}

This research received a financial support from the European Commission, Directorate-General for Agriculture and Rural Development, under Grant Agreement 211708 and from the Commission of the European Communities, FP7, KBBE-2007-1. This paper does not necessarily reflect the view of these institutions and in no way anticipates the Commission's future policy in this area. Hélène Soyeurt, a postdoctoral researcher, and Nicolas Gengler, a research associate, acknowledge the support of the National Fund for Scientific Research (Brussels, Belgium) for these positions and for the additional grants 2.4507.02F (2) and F.4552.05 (2.4.623.08.F). Ministry of Agriculture of the Walloon Region of Belgium (Service public de Wallonie, Direction générale de l'Agriculture, des Ressources naturelles et de l'Environnement, Direction de la Recherche) is acknowledged for their financial support through the project NovaUdderHealth (D31-1207). The authors acknowledge the technical support provided by the Walloon Breeding Association (Ciney, Belgium), Convis Herdbuch (Ettelbruck, Luxembourg), and the milk laboratory (Comité du Lait, Battice, Belgium).

\section{REFERENCES}

Coffey, M. P., G. Simm, J. D. Oldham, W. G. Hill, and S. Brotherstone. 2004. Genotype and diet effects on energy balance in the first three lactations of dairy cows. J. Dairy Sci. 87:4318-4326.
Coleman, J., K. M. Pierce, D. P. Berry, A. Brennan, and B. Horan. 2009. The influence of genetic selection and feed system on the reproductive performance of spring-calving dairy cows within future pasture-based production systems. J. Dairy Sci. 92:5258-5269.

Collomb, M., and T. Bühler. 2000. Analyse de la composition en acides gras de la graisse de lait. Mitt. Lebensm. Hyg. 91:306-332.

Dal Zotto, R., M. De Marchi, A. Cecchinato, M. Penasa, M. Cdro, P. Carnier, L. Gallo, and G. Bittante. 2008. Reproducibility and repeatability of measures of milk coagulation properties and predictive ability of mid-infrared reflectance spectroscopy. J. Dairy Sci. 91:4103-4112.

Hruschka, W. R. 1987. Data analysis: Wavelength selection methods. Pages 35-55 in Near-Infrared Technology in the Agricultural and Food Industries. P. Williams, and K. Norris, ed. American Association of Cereal Chemists, St Paul, MN.

ISO. 2001. Milk and milk products. Extraction methods for lipids and liposoluble compounds. ISO 14156 :2001; IDF 172:2001. International Organisation for Standardisation, Geneva, Switzerland.

ISO. 2002. Milk fat. Preparation of fatty acid methyl esters. ISO 15884:2002; IDF 182:2002. International Organisation for Standardisation, Geneva, Switzerland.

Jensen, R. G. 1995. Handbook of Milk Composition. Academic Press, San Diego, CA.

Prendiville, R., E. Lewis, K. M. Pierce, and F. Buckley. 2010. Comparative grazing behavior of lactating Holstein-Friesian, Jersey, and Jersey $\times$ Holstein-Friesian dairy cows and its association with intake capacity and production efficiency. J. Dairy Sci. 93:764774 .

Rutten, M. J. M., H. Bovenhuis, K. A. Hettinga, H. J. F. Van Vanlenberg, and J. A. M. van Arendonk. 2009. Predicting bovine milk fat composition using infrared spectroscopy based on milk samples collected in winter and summer. J. Dairy Sci. 92:6202-6209.

Soyeurt, H., P. Dardenne, F. Dehareng, C. Bastin, and N. Gengler. 2008b. Genetic parameters of saturated and monounsaturated fatty acid content and the ratio of saturated to unsaturated fatty acids in bovine milk. J. Dairy Sci. 91:3611-3626.

Soyeurt, H., P. Dardenne, F. Dehareng, G. Lognay, D. Veselko, M. Marlier, C. Bertozzi, P. Mayeres, and N. Gengler. 2006. Estimating fatty acid content in cow milk using mid-infrared spectrometry. J. Dairy Sci. 89:3690-3695.

Soyeurt, H., F. Dehareng, P. Mayeres, C. Bertozzi, and N. Gengler. 2008a. Variation of delta9-desaturase activity in dairy cattle. J. Dairy Sci. 91:3211-3224.

Soyeurt, H., I. Misztal, and N. Gengler. 2010. Genetic variability of milk components based on mid-infrared spectral data. J. Dairy Sci. $93: 1722-1728$.

Westerhaus, M. O. 1990. Improving repeatability of NIR calibrations across instruments. Pages 671-674 in Proc. 3rd Int. Conf. Near Infrared Spectroscopy, Brussels, Belgium. Agricultural Research Centre, Gembloux, Belgium.

Williams, C. M. 2000. Dietary fatty acids and human health. Ann. Zootech. 49:165-180.

Williams, P. 2007. Near-infrared technology — Getting the best out of light. PDK Grain, Nanaimo, Canada.

Williams, P. C., and D. C. Sobering. 1993. Comparison of commercial near infrared transmittance and reflectance instruments for analysis of whole grains and seeds. J. Near Infrared Spectrosc. $1: 25-32$. 